\title{
A Study And Screening of out Patients for Metabolic Syndrome
}

\author{
${ }^{1}$ Dr.Sireesha Maraju, ${ }^{2}$ Dr.Mohana Lakshmi Jonnadula \\ ${ }^{1}$ Assistant Professor, Department of Biochemistry, Guntur Medical College, Guntur. \\ ${ }^{2}$ Assistant Professor, Department of Biochemistry, Guntur Medical College.
}

\section{Introduction}

Metabolic syndrome refers to a cluster of risk factors that are associated with increased risk of development of heart disease and diabetes. Metabolic syndrome is also known as Insulin Resistance Syndrome ${ }^{1}$ or Raven Syndrome or Syndrome X. Many of the characteristics of metabolic syndrome are risk factors associated with either Type II diabetes or heart disease or both. According to National Cholesterol Education Programme (NCEP, ATP-III) guidelines, metabolic syndrome should be diagnosed when three or more of these risk factors ${ }^{2}$ are present.

1. Blood pressure greater than $130 / 85 \mathrm{mmHg}$

2. HDL-cholesterol less than $40 \mathrm{mg} / \mathrm{dl}$ for men and $50 \mathrm{mg} / \mathrm{dl}$ for women.

3. Triglycerides greater than or equal to $150 \mathrm{mg} / \mathrm{dl}$.

4. Fasting Plasma Glucose more than or equal to $110 \mathrm{mg} / \mathrm{dl}$.

5. Waist circumference greater than 40 inches for men, greater than 35 inches for women.

The above syndrome (Syndrome ' $\mathrm{X}$ ' or Metabolic syndrome) refers to cluster of condition that refers to insulin resistance hyper insulinemia, high blood pressure, lipid profile abnormalities include - increased Triglycerides, decreased HDL cholesterol levels and obesity.

Incidence:- According to data from Framingham heart study, by Dr. Meig, Prevalence of metabolic syndrome (as defined by NCEP) increased from about 15-20 percent in men and 7-16 percent in women. Based on National Health and Nutrition Examination Survey (NHANES III), the metabolic syndrome as defined by NCEP, is more common in men than in women and prevalence increases with age. Pathophysiology of Insulin Resistance:- Insulin binds and acts mainly through insulin receptor and also via insulin like growth factor (IGF 1) receptor. Cellular actions of insulin involve a wide variety of effect of post receptor signaling path ways with in target cells. The beta sub unit of insulin receptor is tyrosine kinase - which is activated when insulin binds to alpha sub unit. The kinase activity auto phosphorylates and mediates multiple actions of insulin. Insulin receptor number is affectively regulated by insulin levels, various physiological and disease states and also by drugs.Mechanisms responsible for insulin resistance syndrome include genetic or primary target cell defect, auto antibodies to insulin and accelerated insulin degradation. Insulin resistance is partially inherited and partially due to life style factors.

Insulin resistance plays a major pathognomic role in development of metabolic syndrome that may include.

1. Hyper Insullinemia: Hyper insullinemia leads to insulin resistance and other complications associated with increased risk of cardio vascular disease. Endothelial dysfunction is a prominent feature of Insulin Resistance Syndrome ${ }^{4}$.

2. Type II Diabetes: Characterized by increased hepatic glucose output, increased peripheral resistance to the action of insulin caused by receptor and post receptor defects and impaired insulin secretion ${ }^{5}$. In skeletal muscle - Insulin resistance is caused by various abnormalities including defective Glucose transporter-4.

3. Obesity: Most common cause of insulin resistance and is associated with decreased number of receptor and post receptor failure to activate tyrosine kinase. Fat accumulates in abdominal region increases severity of insulin resistance 6 .

4. Polycystic Ovarian Disease: Insulin and Insulin like Growth Factors are important regulators of ovarian function. Insulin resistance and hyper insullinemia are responsible for hyper androgenism.

5. Hypertension.

6. Dyslipidemia: That includes high triglycerides, Low HDL cholesterol ${ }^{7}$.

7. Hypercoagulability: Characterized by increased plasminogen activator inhibitor-1 level.

Underlying causes of insulin resistance states can be categorized as follows

Pre-receptor : 1) Abnormal insulins (due to mutations) 2) Anti insulin antibodies

Receptor : 1) Decreased number of receptor ( Mainly failure of activity of tyrosine kinase). 
2) Reduced binding of insulin

3) Insulin receptor mutations

4) Insulin receptor blocking antibodies.

Post-receptor :

1) Defective signal transduction

2) Mutations in glucose transporter-4

Pathologic Consequences of Obesity ${ }^{\mathbf{8}}$ :- Obesity is the major risk factor for DM and as many as $80 \%$ patients with NIDDM are obese. Obese persons who do not have DM can synthesize and secrete sufficient insulin to overcome the insulin resistance state. The cause of NIDDM is unknown, but insulin resistance plays primary role. Insulin receptor number and function is decreased and post receptor defect likely cause, uncoupling of hormone occupied receptor from activation of down stream signaling events. A defect in insulin stimulated glucose transport is due to defect in either number or function of GluT-4 that move from intra cellular site to plasma membrane in response to insulin. Obesity is associated with increased levels of free fatty acid a reflection of increased rate of lipid turn over. Cytokine TNF has been implicated as molecular mediator of insulin resistance. TNF expression is increased in obese adipocytes and the level TNF expression at this site correlates with degree of insulin resistance.

Insulin:- Insulin is a protein hormone secreted by beta cells of Islets of langerhans of pancreas. It plays an important role in metabolism causing anabolism of carbohydrate, lipids and proteins like glycogenesis / glycogen storage; FA synthesis / TG storage and aminocid uptake / protein synthesis. This insulin is an important anabolic hormone. Major target tissues of insulin are the muscles, liver, adipose tissue and heart.

Metabolic Role of Insulin:-

(A) Action on Carbohydrate Metabolism:- Net effect is lowering of blood glucose level and increased glycogen stores by increase in glucose uptake, increase in glycolysis, increase in conversion of pyruvate to acetyl $\mathrm{CoA}$, increase in glycogenesis, decrease in gluconeogenesis. decrease in glycogenolysis, increase in HMP shunt.

(B) Action on Lipid Metabolism:-Net effects are $\downarrow$ of FFA level, $\uparrow$ in TG store by decrease in lipolysis, increase in FA synthesis, increase in synthesis of Triglycerides in adipose tissue, decrease in ketogenesis.

(C) Action on Protein Metabolism:- Net effect is insulin promotes protein synthesis by

1. Insulin increases amino acid uptake by the tissues by enhancing the rate of membrane "transportation" for amino acids.

2. Insulin provides more aminoacids, in cells by affecting gene transcription (nuclear level), by regulations specific m-RNA synthesis and affecting translation at ribosome level.

(D) Action on Mineral Metabolism:-

$\downarrow$ in conc. Of $\mathrm{K}^{+}$and inorganic Phosphate in blood due to enhanced glycogenesis and phosphorylation of glucose.

(E) Action on Growth and Cell Replication

Insulin stimulates growth in vivo and also cell prolifention in vitro. Insulin potentiates the abilities of fibroblast growth factor (FGF), platelet derived growth factor (PDGF) and epidermal growth factor (EGF) etc.

\section{Insulin Resistance":-}

Contribution of Hepatic Insulin Resistance :- The importance of increased hepatic gluconeogenesis is underlined by the fact that when phosphoenol pyruvate carboxykinase a regulatory enzyme in gluconeogenesis is over expressed in mice carrying a transgene expressing the protein hyperglycemia .Hepatic glucose production plays a primary role in pathogenesis of human NIDDM.

Contribution of Insulin Resistance in Skeletal Muscle:- In insulin resistant patients with physiologic insulin infusions glycogen synthesis in skeletal muscle is reduced more than oxidative metabolism. When physiologic insulin levels are maintained both muscle glycogen storage and glucose oxidation is impaired. Insulin

Resistance in Adipocytes :- Insulin resistance in adipose tissue may play a role in obese diabetic. The cellular content of Glut-4, the facilitative glucose transporter of adipocytes and skeletal muscle is reduced by $40 \%$ in obese without NIDDM and $85 \%$ in obese persons with NIDDM.

Free Fatty Acids :- Elevated Plasma FFA's in obesity cause insulin resistance by inhibiting muscle glucose metabolism and including hyper-insulinemia through up regulation of low $\mathrm{Km}$ glucose metabolism in 
islets. Fat cells store fuel in the form of triglycerides in time of nutritional abundance and release FFA's and glycerol when food is not available.

Pathophysiology of type 2 DM:- Type 2 DM is characterised by 3 pathological abnormalities.

1. Impaired insulin secretion.

2. Peripheral, Insulin resistance and

3. Excessive hepatic glucose production.

Obesity particularly visceral / central is common in type 2 DM. Insulin resistance associated with obesity augments genetically determined insulin resistance of type $2 \mathrm{DM}$.

\section{Peripheral Insulin Resistance ${ }^{10}:-$}

There is decreased ability of insulin to act effectively on peripheral target tissues that is muscle and liver and it is prominent feature of type $2 \mathrm{DM}^{11}$. So, increased levels of circulating insulin will require normalizing plasma glucose. Resistance to the action of insulin impairs glucose utilization by insulin sensitive tissues and increases hepatic glucose output. These both effects contribute hyperglycemia in diabetes. Increased hepatic glucose output accounts for increased FPG levels, where as decreased peripheral glucose utilization results in post-prandial hyperglycemia. In skeletal muscle, there is greater, impairment in non oxidative glucose usage (glycogen formation) than in oxidative glucose metabolism through glycolysis. Insulin receptors levels and tyrosine kinase activity in skeletal muscle are reduced but these alterations are secondary to hyper-insulinemia. Therefore post receptors defects play predominant role in insulin resistance.Pathogenesis of insulin resistance focuses on PIP-3 kinase (phosphoinositol phosphate 3-kinase) signaling defect, which causes reduced translocation of GluT $-4^{12}$ to plasma membrane. Consequently hyper-insulinemia may increase the insulin action.

Impaired Insulin Secretion :- Insulin secretion and sensitivity are inter-related. In type $2 \mathrm{DM}$, insulin secretion initially increases in response to insulin resistance to maintain normal glucose tolerance. Initially insulin secretary defect is mild and involves glucose stimulated insulin secretion. Insulin secretory defect progresses to a state of inadequate insulin secretion. Some endogenous insulin production continues but the amount secreted is less than the amount secreted by normal individuals at same plasma glucose concentration.

Increased Hepatic Glucose Production:- Liver maintains plasma glucose during periods of fasting through glycogenolysis and gluconeogenesis using substrates derived from skeletal muscle and fat (alanine, lactate, glycerol, and fatty acids). Insulin promotes the storage of glucose as hepatic glycogen and suppresses gluconeogenesis which results in fasting hyperglycemia and decreased storage by liver in postprandial state. Increased hepatic glucose production occurs early in diabetes.

\section{Insulin Resistance Syndrome ${ }^{13}:-$}

It comprises a spectrum of disorders with hyperglycemia syndrome ' $\mathrm{X}^{, 14}$ used to describe constellation of metabolic derangements that include insulin resistance, hypertension, dyslipidemia, central or visceral obesity, endothelial dysfunction and accelerated cardiovascular diseases. Hyper-insulinemia is a marker for coronary artery disease $\mathrm{e}^{15}$.

\section{Poly Cystic Ovary Syndrome ${ }^{16}$ :-}

Disorder that affects premenopausal women, characterised by chronic anovulation and hyperandrogenism. Insulin resistance is seen in women with PCOS and the disorder substantially increases the risk for type $2 \mathrm{DM}$, independent of effects of obesity.

Prevention ${ }^{17}$ :-Type $2 \mathrm{DM}$ is preceded by a period of IGT, life style modifications ${ }^{18}$ and pharamacological agents ${ }^{19}$.

\section{Materials And Methods}

Controls:-Controls were selected on the basis of ideal body weight with no systemic illness and in good health. 96 patients were studied against 12 controls of 30-60 years of age group.

Cases:- For the present study patients presenting with obesity and increased body weight were selected. In our present study, cases were divided into three groups depending upon their number of positive risk factors. Cases having less than three risk factors were placed in Group I. Cases having three risk factors were placed in Group II. Cases having more than three risk factors were placed in Group III. Cases with three or more than three risk factors were diagnosed for metabolic syndrome, according to National Cholesterol Education Programme NCEP, ATP III guide lines. All cases and controls were asked to come to biochemistry laboratory on overnight fasting at 9 A.M. After brief clinical examination i.e. taking relevant history, recording 
blood pressure, measuring waist circumference and blood sample was taken for the measurements of following parameters-- Estimation of plasma glucose(FPG), Lipid profile(Total triglycerides,HDL ) levels.

\section{Results}

\begin{tabular}{|c|c|c|c|c|c|c|c|}
\hline \multicolumn{8}{|c|}{ Comparative Study of Group I Cases with Controls } \\
\hline No. & Parameters & \multicolumn{2}{|l|}{ Control } & \multicolumn{2}{|c|}{ Group I } & & Significance \\
\hline \multirow[t]{2}{*}{1} & \multirow[t]{2}{*}{ HDL } & & \multirow[t]{2}{*}{4.13} & & & \multirow[t]{2}{*}{3.2} & \multirow[t]{2}{*}{$<0.01$} \\
\hline & & $43.83 \pm$ & & 38 & \pm & & \\
\hline \multirow[t]{2}{*}{2} & TGL & & \multirow[t]{2}{*}{17.25} & & & \multirow[t]{2}{*}{30.91} & \multirow[t]{2}{*}{$<0.01$} \\
\hline & & 108 & & 147 & \pm & & \\
\hline \multirow[t]{2}{*}{3} & Waist & & \multirow[t]{2}{*}{2.1} & & & \multirow[t]{2}{*}{3.5} & \multirow[t]{2}{*}{$<0.05$} \\
\hline & Circumerence & 36.5 & & 39.12 & \pm & & \\
\hline \multirow[t]{2}{*}{4} & Systolic B. P & & & & & \multirow[t]{2}{*}{8.68} & \multirow[t]{2}{*}{$>0.05$} \\
\hline & & 114.16 & & 119.2 & \pm & & \\
\hline \multirow[t]{2}{*}{5} & Diastolic B. P. & & \multirow[t]{2}{*}{5.14} & & & \multirow[t]{2}{*}{6.4} & \multirow[t]{2}{*}{$>0.05$} \\
\hline & & 75.83 & & 74.3 & \pm & & \\
\hline \multirow[t]{2}{*}{6} & FPG & & \multirow[t]{2}{*}{5.0} & & & \multirow[t]{2}{*}{9.2} & \multirow[t]{2}{*}{$<0.01$} \\
\hline & & 73.6 & & 90 & \pm & & \\
\hline
\end{tabular}

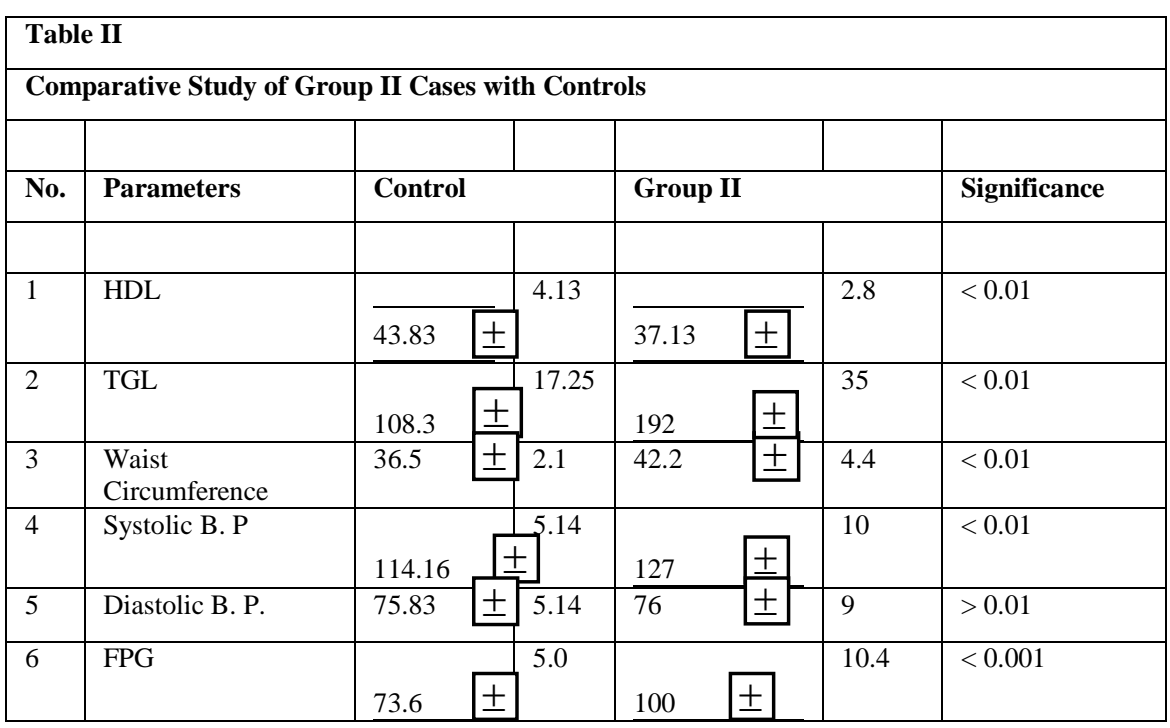

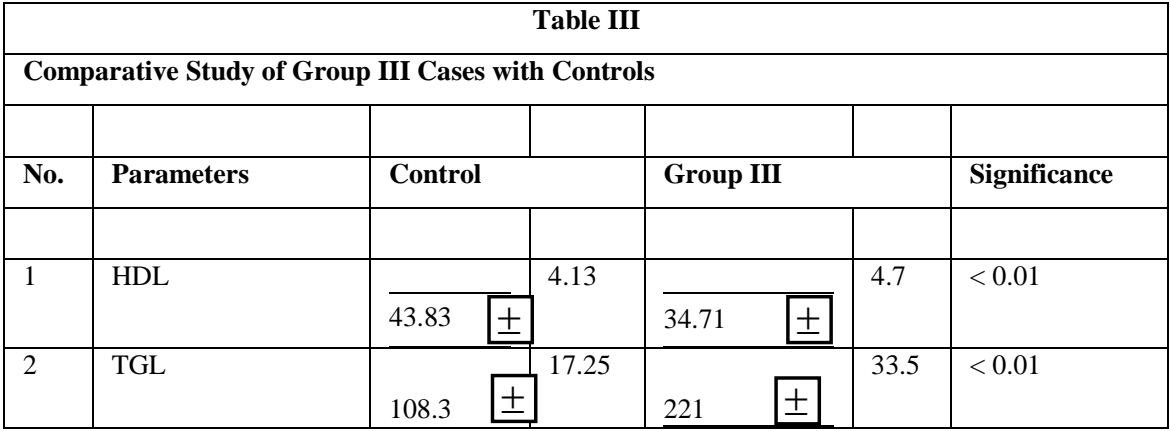




\begin{tabular}{|c|c|c|c|c|c|c|c|}
\hline 3 & Waist Circumference & 36.5 & 2.1 & 42.28 & \pm & 2 & $<0.01$ \\
\hline 4 & Systolic B. P & = & 5.14 & 138 & & 6.9 & $<0.01$ \\
\hline 5 & Diastolic B. P. & 75.83 士 & 5.14 & 88 & \pm & 3.7 & $<0.01$ \\
\hline 6 & FPG & $73.6 \quad \pm$ & 5.0 & 107 & \pm & 3.13 & $<0.001$ \\
\hline
\end{tabular}

Table IV

Comparative Study of Group I Cases with Group II

\begin{tabular}{|c|c|c|c|c|c|c|c|}
\hline No. & Parameters & \multicolumn{2}{|c|}{ Group I } & \multicolumn{3}{|c|}{ Group II } & Significance \\
\hline 1 & HDL & 38 & \pm 3.2 & 37.13 & \pm & 2.8 & $>0.05$ \\
\hline 2 & TGL & 147 & \begin{tabular}{|l|} 
\pm \\
\pm
\end{tabular} & 192 & \pm & 35 & $<0.01$ \\
\hline 3 & Waist Circumference & 39.12 & \pm 3.5 & 42.2 & \pm & 4.4 & $<0.01$ \\
\hline 4 & Systolic B. P & 119.21 & \pm 3.68 & 127 & \pm & 10 & $<0.01$ \\
\hline 5 & Diastolic B. P. & 74.3 & \begin{tabular}{|l|l} 
\pm & 6.4 \\
\end{tabular} & 76 & \pm & 9 & $>0.05$ \\
\hline 6 & FPG & $\underline{90}$ & \begin{tabular}{|l|l} 
\pm & 9.2 \\
\end{tabular} & 100 & \pm & 10.4 & $<0.01$ \\
\hline
\end{tabular}

Table V

Comparative Study of Group I Cases with Group III

\begin{tabular}{|c|c|c|c|c|c|c|c|c|}
\hline No. & Parameters & \multicolumn{3}{|c|}{ Group I } & \multicolumn{3}{|c|}{ Group III } & Significance \\
\hline 1 & HDL & 38 & \pm & 3.2 & 34.71 & \pm & 4.7 & $<0.05$ \\
\hline 2 & TGL & 147 & \pm & 30.91 & \multirow{2}{*}{$\frac{221}{42.28}$} & \pm & 33.5 & $<0.01$ \\
\hline 3 & Waist Circumference & 39.12 & \pm & 3.5 & & \pm & 2.01 & $<0.05$ \\
\hline 4 & Systolic B. P & 119.21 & \pm & 8.68 & 138 & \pm & 6.9 & $<0.01$ \\
\hline 5 & Diastolic B. P. & 74.3 & \pm & 6.4 & 88 & \pm & 3.7 & $<0.01$ \\
\hline 6 & FPG & 90 & \pm & 9.2 & 107 & \pm & 3.13 & $>0.01$ \\
\hline
\end{tabular}

Table VI

Comparative Study of Group II Cases with Group III

\begin{tabular}{|c|c|c|c|c|c|c|c|}
\hline No. & Parameters & \multicolumn{2}{|c|}{ Group II } & \multicolumn{3}{|c|}{ Group III } & Significance \\
\hline 1 & HDL & 37.13 & \pm 2.8 & 34.71 & \pm & 4.7 & $>0.05$ \\
\hline & TGL & 192 & $\pm \sqrt{35}$ & 221 & \pm & 33.5 & $>0.05$ \\
\hline 3 & Waist Circumference & 42.2 & \pm 4.4 & 42.28 & \pm & 2.01 & $>0.01$ \\
\hline 4 & Systolic B. P & & 10 & & . & 6.9 & $<0.05$ \\
\hline
\end{tabular}




\begin{tabular}{|c|c|c|c|c|c|c|c|}
\hline & & 127 & & 138 & & & \\
\hline 5 & Diastolic B. P. & 76 & \pm 9 & 88 & & 3.7 & $<0.01$ \\
\hline 6 & FPG & 100 & $\pm_{10.4}$ & 107 & \pm & 3.13 & $>0.05$ \\
\hline
\end{tabular}

HDL Comparison Diagram

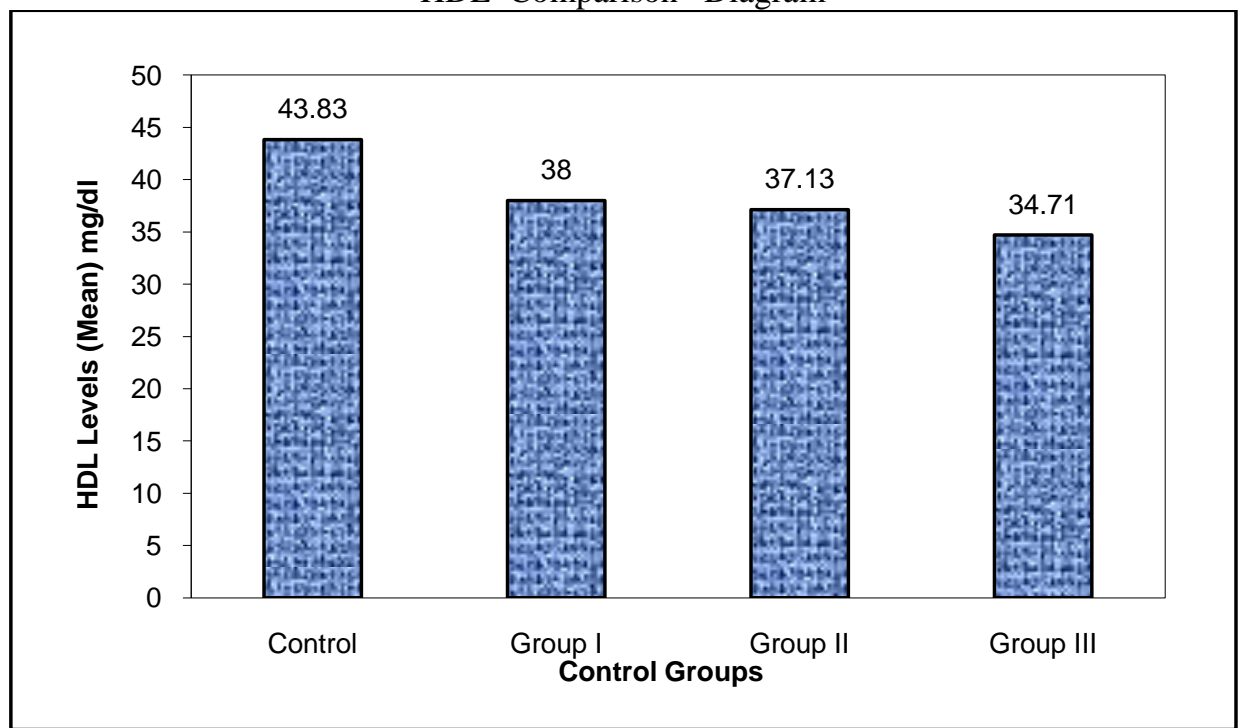

TGL Comparison Diagram

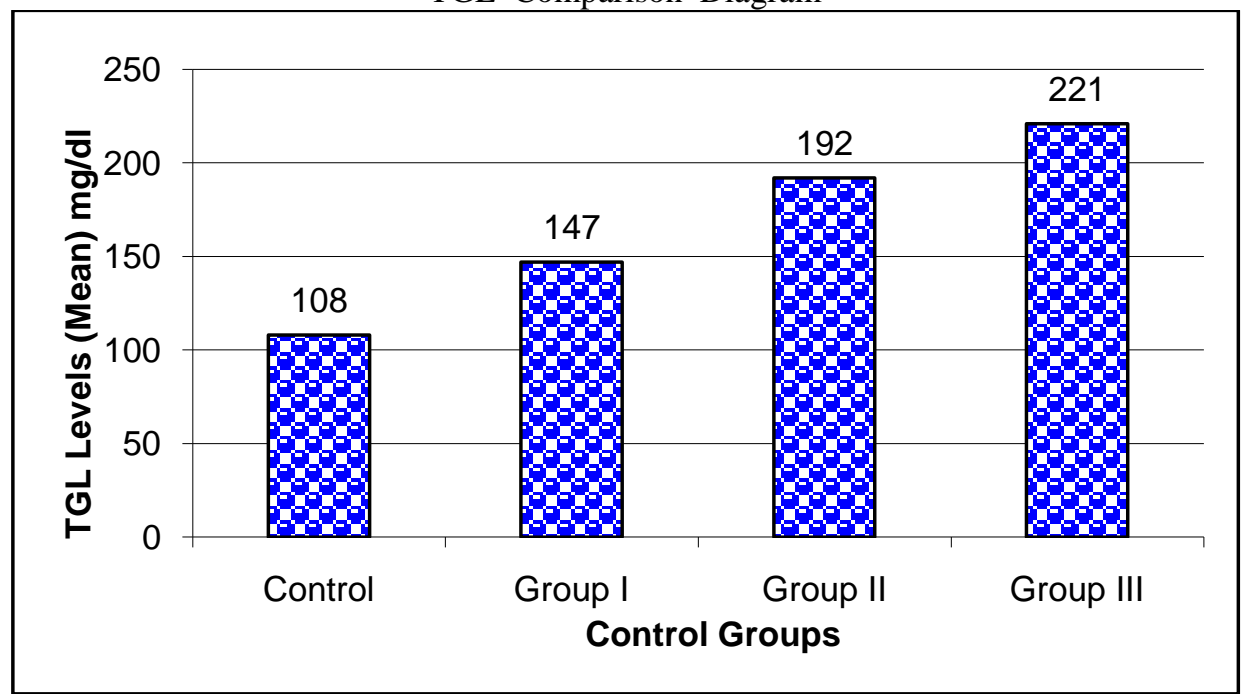


Waist Circumference Comparison Diagram

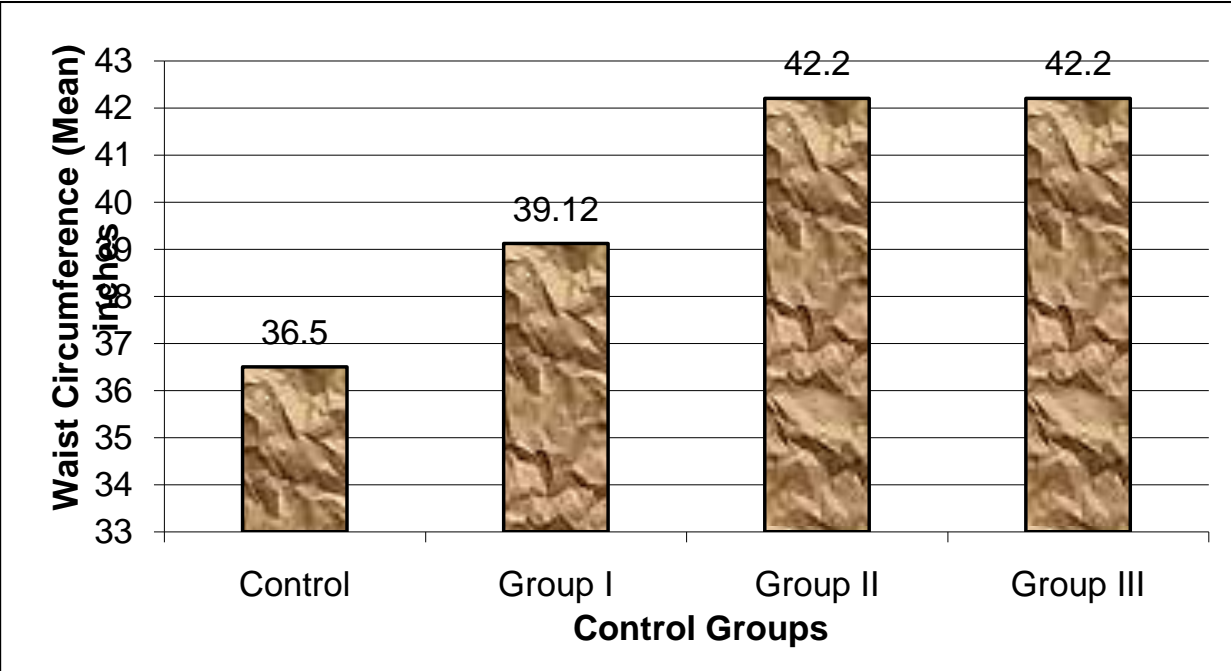

Systolic Blood Pressure Comparison Diagram

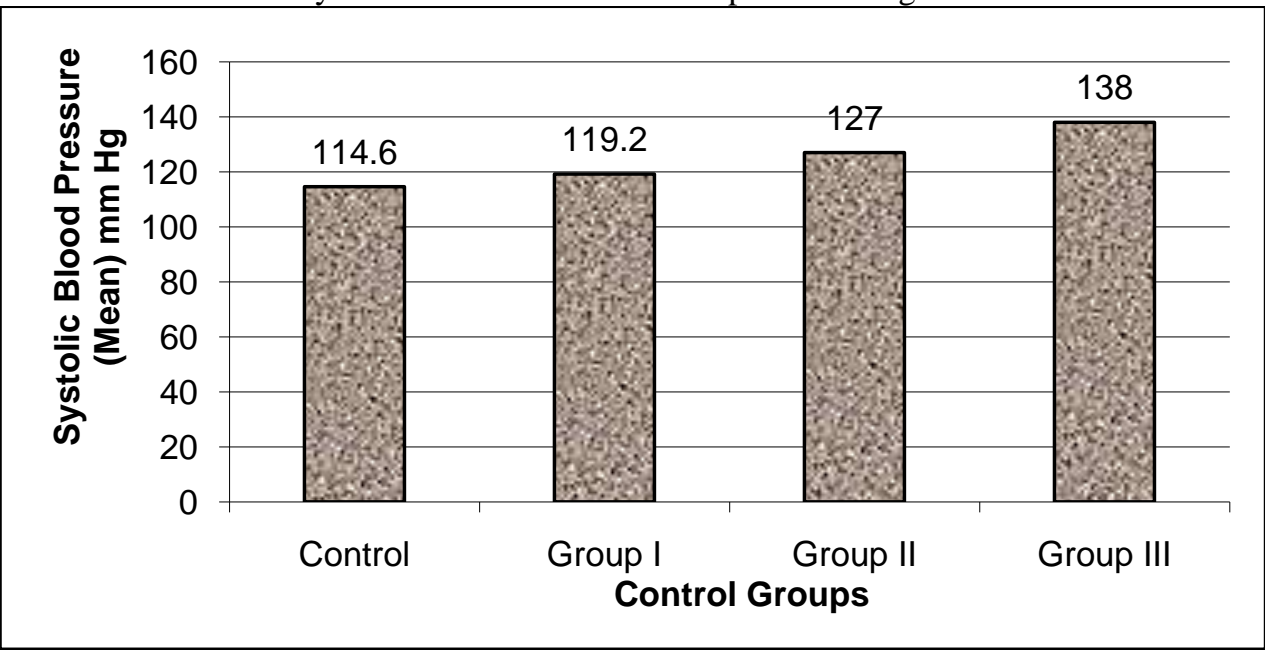

DIASTOLIC BLOOD PRESSURE COMPARISON DIAGRAM

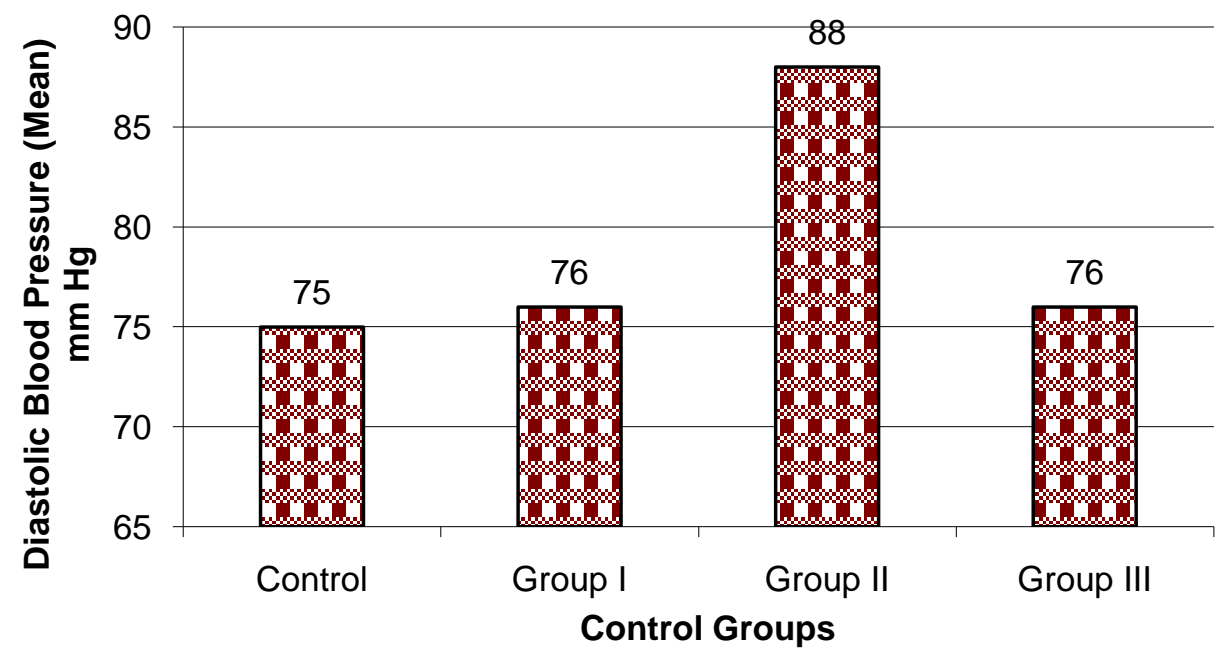


Fasting Plasma Glucose Comparison Diagram

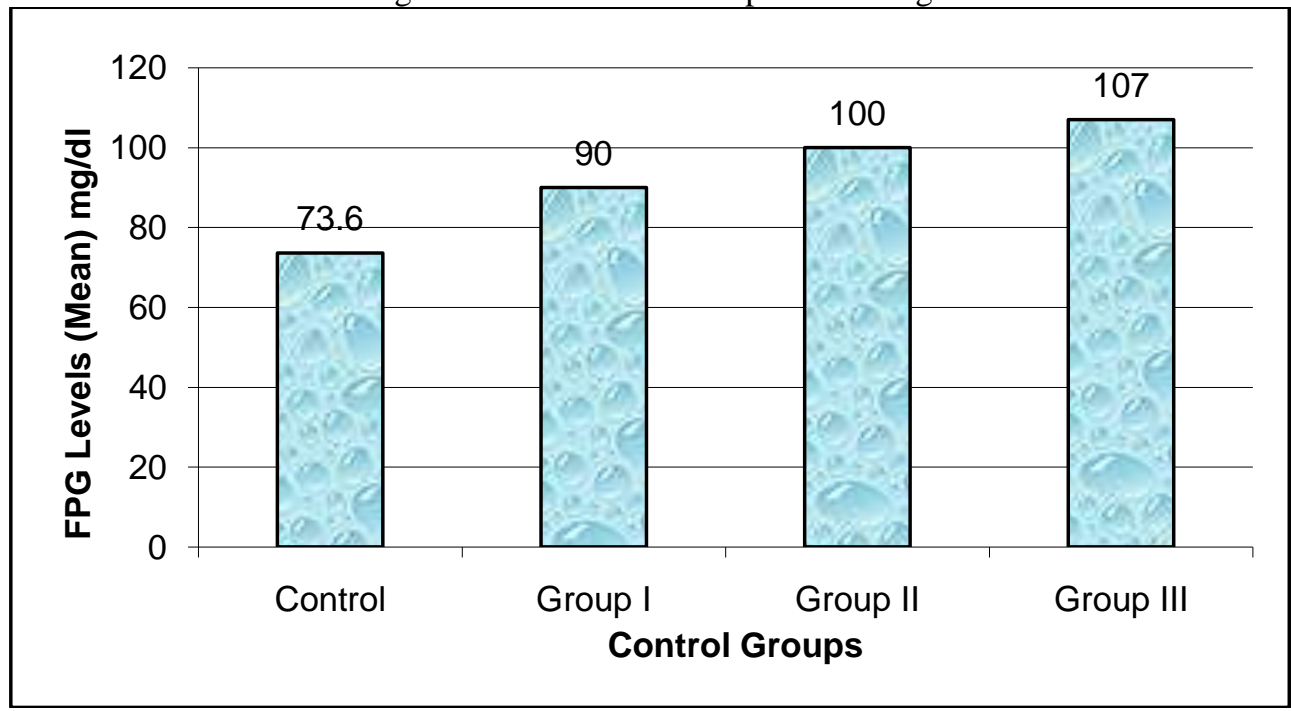

\section{Discussion}

Risk assessment of metabolic syndrome based on NCEP ATP - III guide lines states that presence of 3 or more of risk factors indicates future development of metabolic syndrome and risk of heart disease and type 2 diabetes and complications related to nervous system, kidney failure, diabetic retinopathy etc. In our present study screening of 96 cases was done and about $47 \%$ of cases having 3 or more than 3 risk factors are cases of

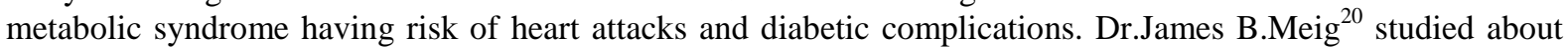
conditions seen in suspected cases of metabolic syndrome and he diagnosed those patients suffering with metabolic syndrome as having low HDL ${ }^{21}$, high triglycerides and increased waist circumference. Risk of heart disease was higher in those patients with high levels of fasting plasma glucose. In our present study cases are categorized under Group I, Group II and Group III and are compared with controls. Group III cases with risk factors more than 3 are showing more significance and Group II cases with risk factors of 3 are showing significance towards developing heart attacks. Group I cases that is less than 3 risk factors are showing less risk of heart attacks and proceeding towards metabolic syndrome. From the current study we can deduce that the risk is continually increasing with rise of each of 5 parameters linearly.

Approx half of screening cases (about 47\%) are at more risk of developing further complications ${ }^{22}$ and they can be prevented by taking suitable life style modifications.

O Increased physical activity / exercise.

$\mathrm{O}$ Weight reduction.

O Low-caloric diet.

\section{Dr.Reddy, Chairman, Department of Endocrinology ${ }^{23}$}

He stated that moderate life style changes can have a significant impact in persons who are overweight or those who have diabetes or insulin resistance. He also stated that making changes in diet can significantly reduce the risk of developing diabetes as well as heart disease. Increased Physical Activity / Exercise ${ }^{24}$ :Exercise improves insulin sensitivity. Regular sustained moderate increase in physical activity such as daily brisk walking, running, bicycling, etc.,substantially decrease insulin resistance. Physical activity has been found to increase the body sensitivity to insulin.

\section{Exercise improves insulin sensitivity and causes increased glucose utilization by}

$\mathrm{O}$ Increased activities of oxidative enzymes

O Increased activity of glucose transporter (GLUT-4)

O Increased vascularity

O Reduces central Obesity

Weight Reduction:- Weight reduction improves insulin sensitivity in obese patients and most of insulin resistant states that are associated with obesity.

Low-caloric Diet:- Insulin sensitivity improves with calorie restriction and low calorie diet causes weight loss. The amount of dietary fibre consumed is inversely related to insulin levels. A diet high in vegetables and fruits helps to combat insulin resistance rather than that of high calorie food stuff. 
Lifestyle modifications reduce morbidity and prevent complications.

\section{Conclusion}

Measurement of HDL, TGL, Waist Circumference, Blood Pressure and Fasting Plasma Glucose parameters are useful as screening tools for assessing level of risk of complications of insulin resistance and for detection of metabolic syndrome. In our present study depending upon number of risk factors present, the selected patients are classified into three groups with increased order of risk. The study shows that Group I which is not included under metabolic syndrome may also have the risk of development of complications of metabolic syndrome, as risk is linearly increasing with deviation of parameters from normal. Group II and Group III comes under metabolic syndrome. On measurement of HDL, TGL, Waist Circumference, Blood Pressure and Fasting Plasma Glucose, the risk of complications can be assessed and preventive measures can be initiated and health can be restored.

\section{References}

[1]. Insulin Resistance Syndrome - Dr. Gowtham Rao, M.D., University of Pittsburgh Medical Centre, St. Margaret, Pitts burgh, Pennsylvania

[2]. Defronzo, R.A., Ferrarnini, E., Insulin resistance. A multifaceted syndrome responsible for NIDDM, Obesity, hypertension, dyslipidemia and atherosclrotic cardio vascular disease. Diabetes care, 1991; $14: 173$ - 94.

[3]. Incremental life style charges can ward if syndrome X - by Dr. Reddy, Chariman, Department of Endocrinology, Diabetes and Metabolism, Cleveland Clinic Foundation.

[4]. Hunter SJ, Garvey WT : Insulin Action and Insulin Resistance : Diseases involving defects in insulin receptors, signal transduction and the glucose from post effector system, Am J Med 1998, 105(4) : 331 - 45(Medline)

[5]. Lindeman, R.D., Romero, L.J., Hundley, R., Prevalence of type 2 diabetes, the insulin resistance syndrome and coronary heart disease in an elderly, biethnic population, Diabettes care, 1998, June : 21(6) : 959 - 66 (Medline)

[6]. Takala, J.K., Vanhala, M.J., Pitkajarvi, T.K., Kumpusalo, E.A., Obesity type and clustering of insu lin resistance associated cardiovascular ride factors in middle aged men and women. Inf, J obes Rolat Metab. Disord; $1998: 22: 369$ - 74.

[7]. Garg, A., Insulin resistance in pathogenesis of dyslipidemia. Diabetes care, 1966; $19: 387$ - 9.

[8]. National Institute of Health, Clinical guidelines on the Identification, Evaluation and Treatment of Over Weight and Obesity in Adults; Bethesda, Maryland, Department of Health and Human Services, National Institutes of Health, National Heart, Lung, and Blood Institute, 1998.

[9]. Williams Text Book of Endocrinology, $9^{\text {th }}$ Edition( $\left.1069,1077-78\right)$

[10]. Insulin Resistance - by Samuel Olatunbosum M.D - Consulting Staff, Department of Internal Medicine - Abstract, 2002.

[11]. Insulin Resistance : At the root of type 2 diabetes by Robert, S. Dinsmoor, May 2000.

[12]. Shepherd, PR, Kahn, B.B., Glucose transporters and Insulin action - implications for insulin resistance

[13]. Liese, A.D., Mayer - Davis., E.J., Haffner, S.M., Development of Insulin resistance syndrome : An epidemiologic perspective. Epidemiology Rev. 1998; $20: 157$ - 72.

[14]. Trevisan, M., Liuj., Bahsas F.B., Menotti, A., Syndrome X and mortality : A population based study. AMJ epidemiology, 1998 : $148: 958-66$

[15]. Pyorala, M., Miettinen, H., Halogen, P., et.al. Insulin resistance syndrome predicts the risk of coronary heart disease and stroke in healthy middle aged men. The 22 year follow up results of the Helsinki policemen study. Arterioscler Thromb Vasc. Biol 2000 : $20: 538-44$.

[16]. American Association of Clinical Endocrinologists by Dr.Helena Rodbard, MD

[17]. Prevention and Treatment of Metabolic Syndrome - by Dr. Scott M. Grundy, M. D., Ph. D., Published in Conference at National Institute of Health, Clinical Guidelines on Identification, Evaluation and Treatment of Overweight and Obesity in Adults at Bethesda, Maryland, 2003.

[18]. Weinstock, R.S., Dai, H., Wadden, J.A., Diet and Exercise in treatment of Obesity : Effects of 3 Interventions on Insulin Resistance, Aren ........ Med, 1998, $158: 2477-83$.

[19]. Saltiel, A.R., Olefsky, J.M., Thaiazolidinediones in the treatment of Insulin resistance and type II diabetes. Diabetes 1996 : 45 : 1661-9.

[20]. Dr. James B. Meigs, M. D. - Paper Published in Conference in National Institute of Health, Clinical Guidelines on Identification Evaluations and Treatment of Over Weight and Obesity, Bethesda Maryland, 2003.

[21]. Karhappap, Malkkim, Laaksom, Isolated low HDL Cholesterol. An Insulin resistant state. Diabetes, $1994: 43: 43: 411$ - 7.

[22]. Ludwig, D.S., Pereira, M.A., Kroenke, C.H., Hilner, J.E., Van Horn, L., Slattery, M.L., et.al. Dietary fibre, weight gain, and cardio vascular disease risk factors in young adults.

[23]. Dr. Reddy, Chariman, Department of Endocrinology, Cleveland Clinic Foundation. On Incremental Life Style Changes can Ward Off-Syndrome X.

[24]. Mayer - Davis, E.J., D' Agostino, R, Karter, A.J., Haffner, S.M., Rewers, M.J., Saad, M. et.al. Intensity and amount of physical activity in relation to Insulin sensitivity : The Insulin resistance atherosclerosis study, JAMA, $1998: 279: 669$ - 74. 